\title{
Innovative methods to promote optics at school level
}

\section{Amit Garg, Sadashiv Raj Bharadwaj, Priyanka Kachru, Subhajit Kumar Dutta, Shatakshi Singh}

Amit Garg, Sadashiv Raj Bharadwaj, Priyanka Kachru, Subhajit Kumar Dutta, Shatakshi Singh, "Innovative methods to promote optics at school level," Proc. SPIE 9946, Optics Education and Outreach IV, 994618 (27 September 2016); doi: 10.1117/12.2245220

SPIE Event: SPIE Optical Engineering + Applications, 2016, San Diego, California, United States 


\title{
Innovative methods to promote optics at school level
}

\author{
Amit Garg, Sadashiv Raj Bharadwaj, Priyanka Kachru, Subhajit Kumar Dutta, Shatakshi Singh \\ Department of Electronics, Acharya Narendra Dev College, University of Delhi, Govindpuri, \\ Kalkaji, New Delhi-110019, India \\ Email:amit_ande@yahoo.co.in
}

\begin{abstract}
1. ABSTRACT
The conventional pedagogical techniques in Indian schools are predominantly limited to coursework and involve just necessary laboratory work. It lacks in inculcating the aptitude for practical applications relevant to the coursework amongst the students. This results in a major setback for the students as their mental approach remains constrained to books, where on the contrary, the future depends only on technologies and applications. Considering this, under Optics Outreach Education Program 2014, University of Delhi at Acharya Narendra Dev College SPIE Student Chapter conducted workshops in 22 schools of Delhi including various Government schools as well. The workshop zeroed into the concepts of optics and various innovative techniques developed by our Student chapter members to embark a new method of teaching.
\end{abstract}

Keywords: Optics Outreach, Wave Optics Kit, Interference, Diffraction, Wave Optics

\section{INTRODUCTION}

As a part of the curriculum of the higher secondary and senior secondary classes in India, students are taught the basics and details of optics including ray optics and wave optics. But the education is limited to theoretical knowledge and not extended using practical or hands-on experience. Lack of practical and hands-on experience restrict the mindset of students, and doesn't allow the inquisitive minds to explore optics to a greater extent. Under Optics Outreach Education Program 2014, University of Delhi at Acharya Narendra Dev College SPIE Student Chapter conducted workshop in 22 schools across Delhi and distributed a Wave Optics Kit conceived and designed by the Chapter to every school free of cost.

The kit allows the students to perform all sorts of experiments listed in their curriculum. These cost effective kits were conceived and designed by the Chapter students. The introduction of such a kit in the school laboratory not only allows the minds to explore the untaught parts of wave optics but also inculcate a sense of learning by self-experiment and an attitude of enquiry.

\section{METHODOLOGY}

We adopted hands on approach to make students understand the basics of ray and wave optics. We divided the students into two batches depending on their classes. The students from 9-10 were categorized as juniors and taught ray optics and the students of classes 11-12 were categorized as seniors and taught wave and fiber optics. The students were given handson knowledge about the apparatus and the procedure. The students were asked to perform the experiments with different width of single slits and observe the changes in patterns obtained. After the completion of the demonstration, the feedback regarding the demonstration were taken. The demonstration was conducted at a moderate pace taking into consideration the progress of every student of the class and their queries.

Optics Education and Outreach IV, edited by G. Groot Gregory, Proc. of SPIE Vol. 9946, 994618

(C) 2016 SPIE · CCC code: $0277-786 X / 16 / \$ 18 \cdot$ doi: $10.1117 / 12.2245220$ 


\section{WAVE OPTICS KIT FEATURES}

The wave optics kits were distributed to all the schools. The contents of designed wave optics kit it as follows:

1. Grating mount with stand

2. LED Lamp with stand

3. Quarter Wave Plate with graduated mount and stand

4. Half Wave Plate with graduated mount and stand

5. Polarizer with graduated mount and stand

6. Analyzer with graduated mount and stand

7. Prism Table with stand

8. Diode Laser mount with stand

9. Prism

10. Hollow Prism

11. Single Slit

12. Double Slit

13. Diffraction Grating

14. Diode Laser with adaptor

15. Glass Slab

16. Multimeter

17. Acrylic Cube

The contents of the kit are shown as below:

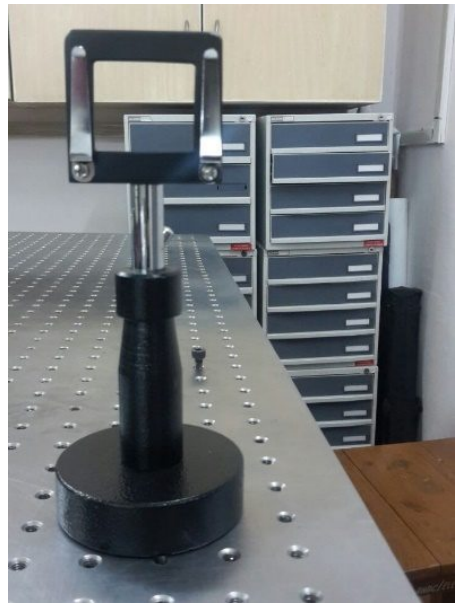

i) Grating Stand

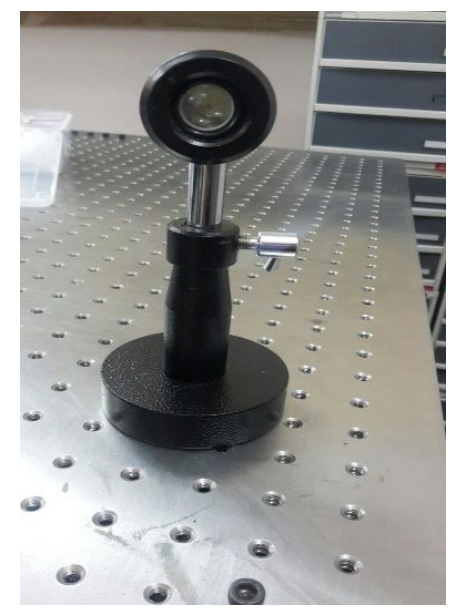

ii) LED Lamp

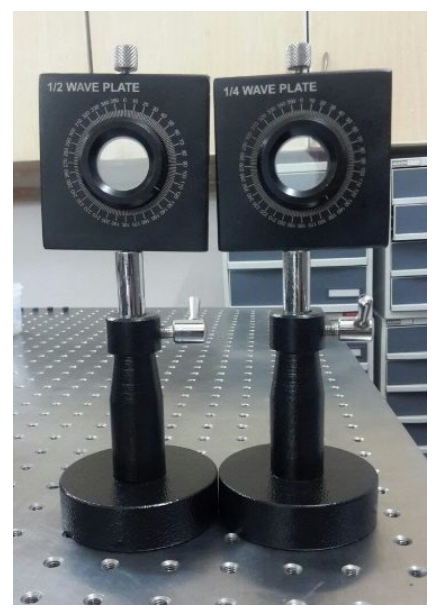

iii) Quarter Wave Plate \& Half Wave Plate 


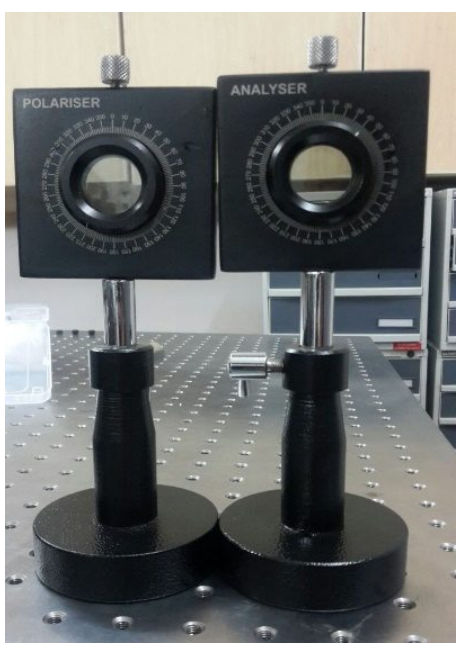

iv) Polarizer \& Analyzer

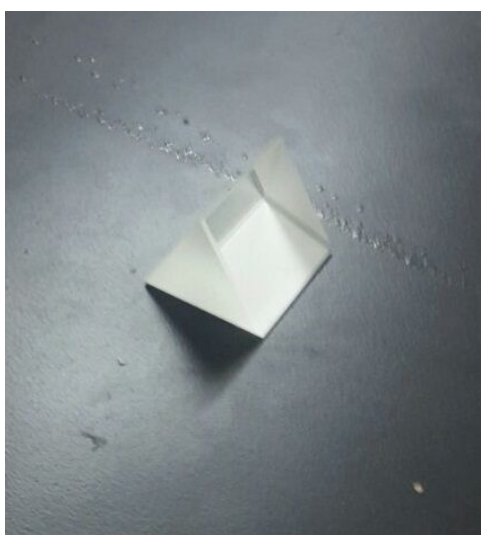

vii) Prism

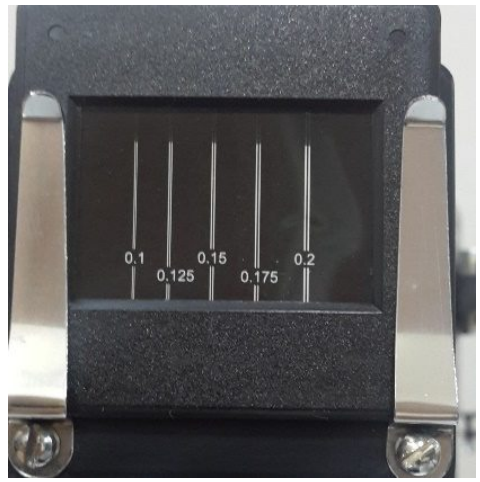

x) Double Slit

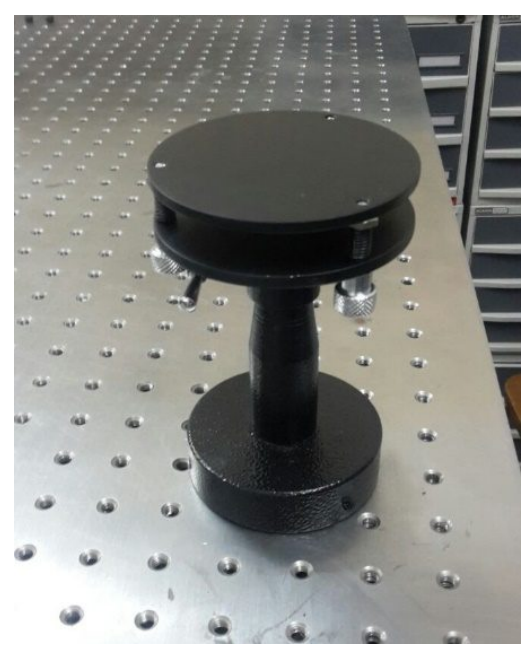

v) Prism Table

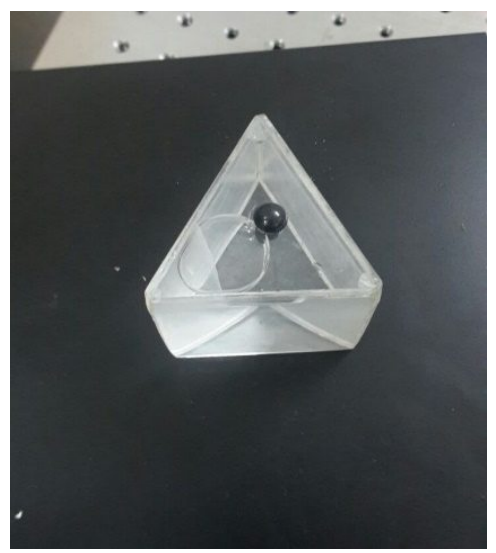

viii) Hollow Prism

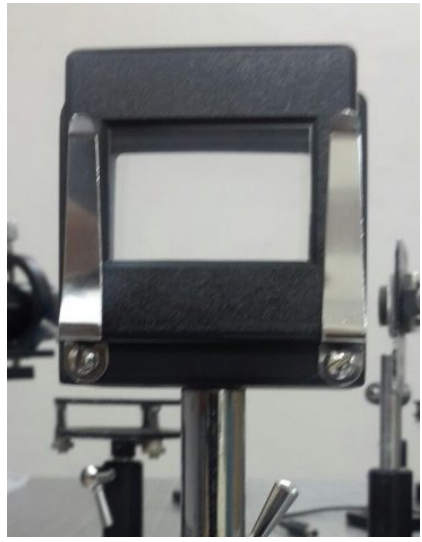

xi) Diffraction Grating

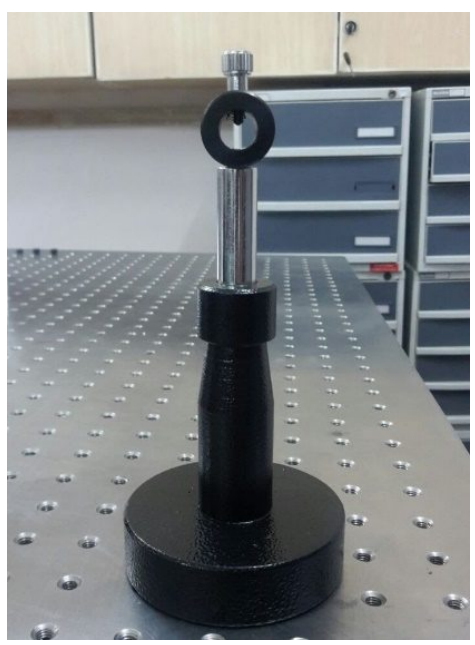

vi) Laser Stand

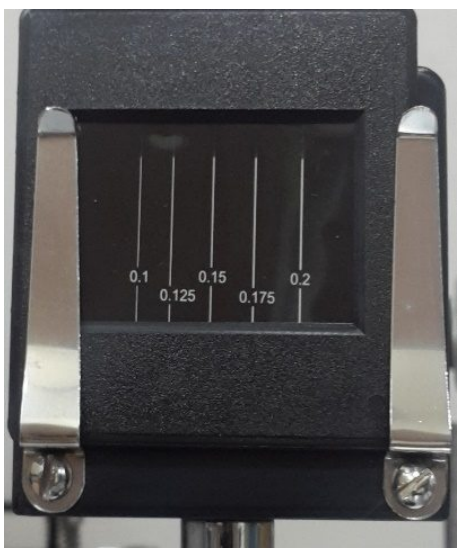

ix) Single Slit

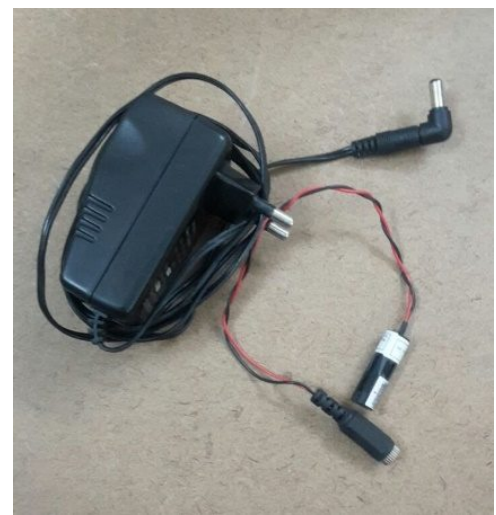

xii) Laser Diode \& Adaptor 


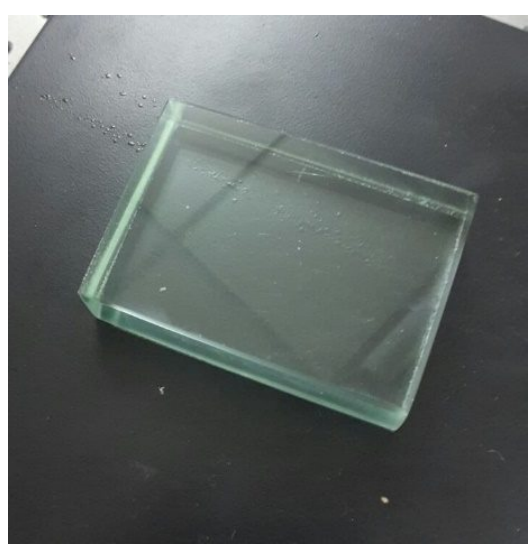

xiii) Glass Slab

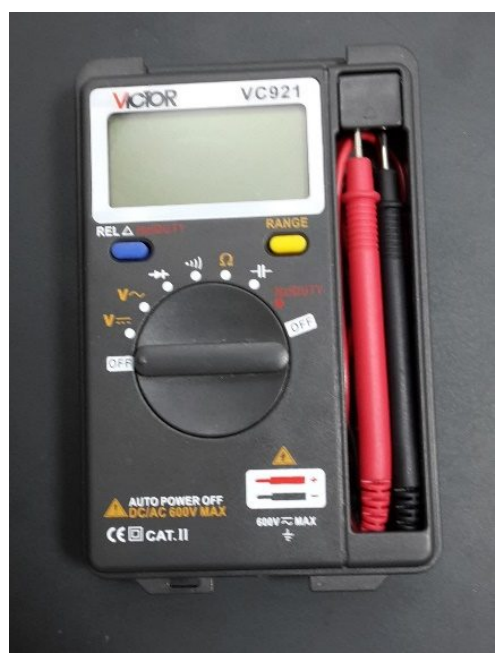

xiv) Pocket Multimeter

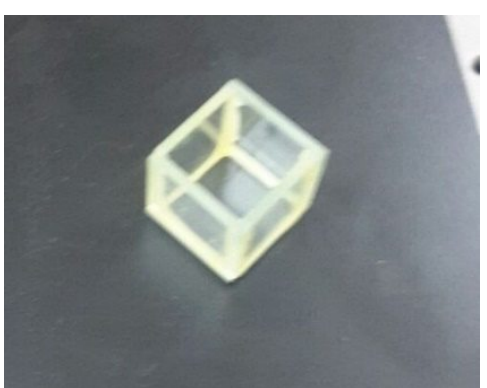

xv) Acrylic cube

The experiments that can be performed with the kit are as follows:

1) Study of polarization and Malus law.

2) Study of refraction of light with glass slab.(Snell's law)

3) Study and demonstration of diffraction of light.

4) Study of behavior of light through $1 / 2$ and $1 / 4$ wave plates.

5) Determination of lateral displacement of laser through glass slab.

6) Study of dispersion of light through glass prism and other liquid prisms.

7) Study of changes in lateral displacement of light upon passing through liquids of different medium.

8) Study of single slit and double slit diffraction of light and their variation with slit width.

9) Study of Brewster's Law.

10) Study of critical angle and total internal reflection.

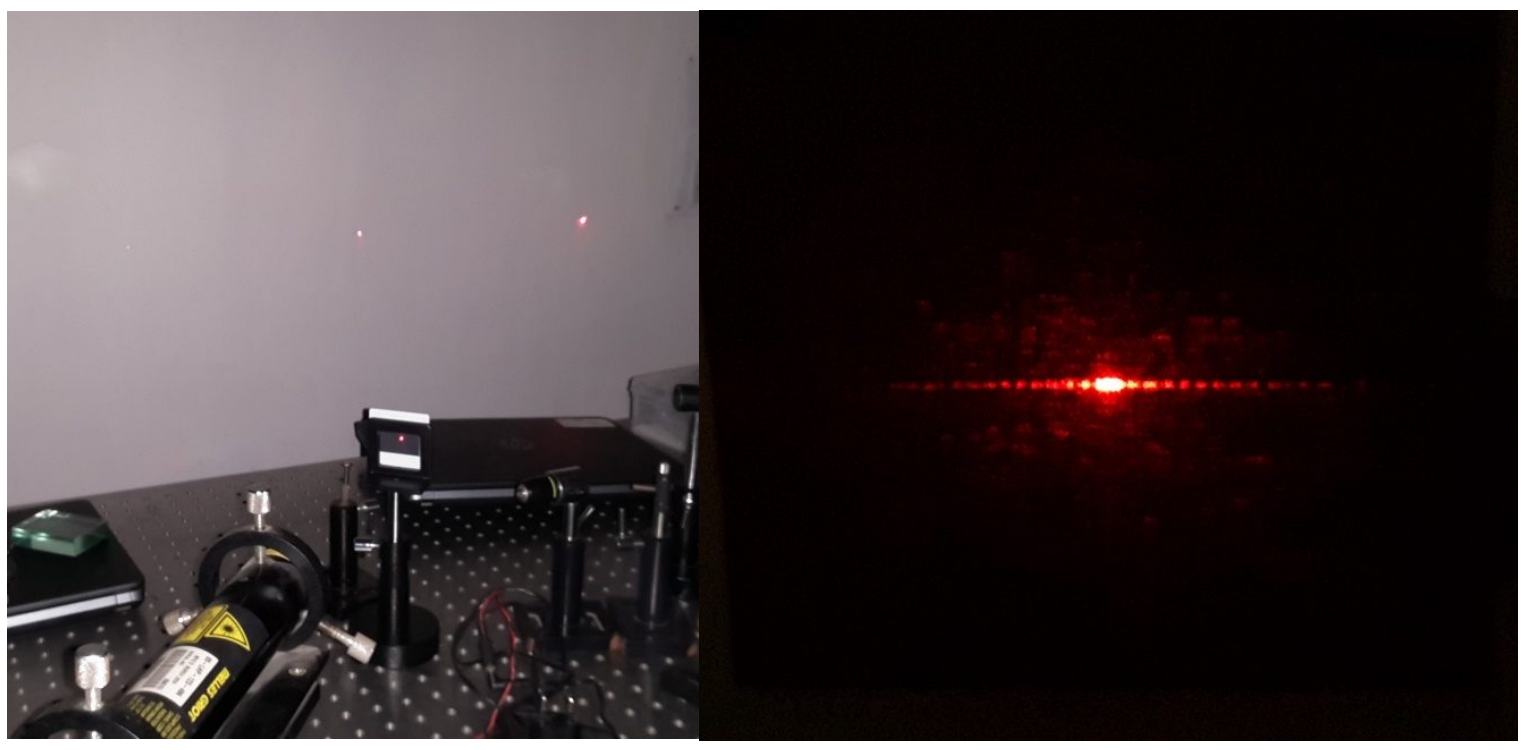

Diffraction of laser through diffraction grating.

Double Slit Diffraction Pattern 


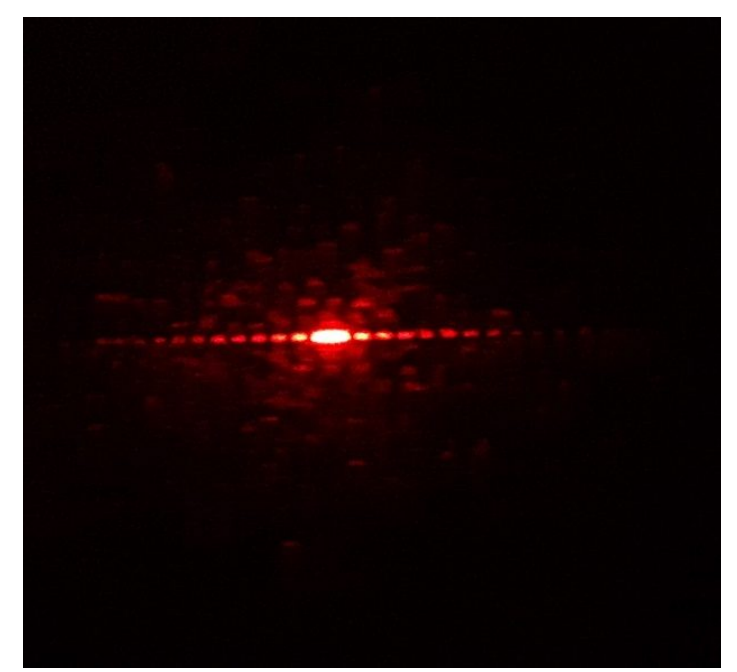

Single Slit Diffraction Pattern

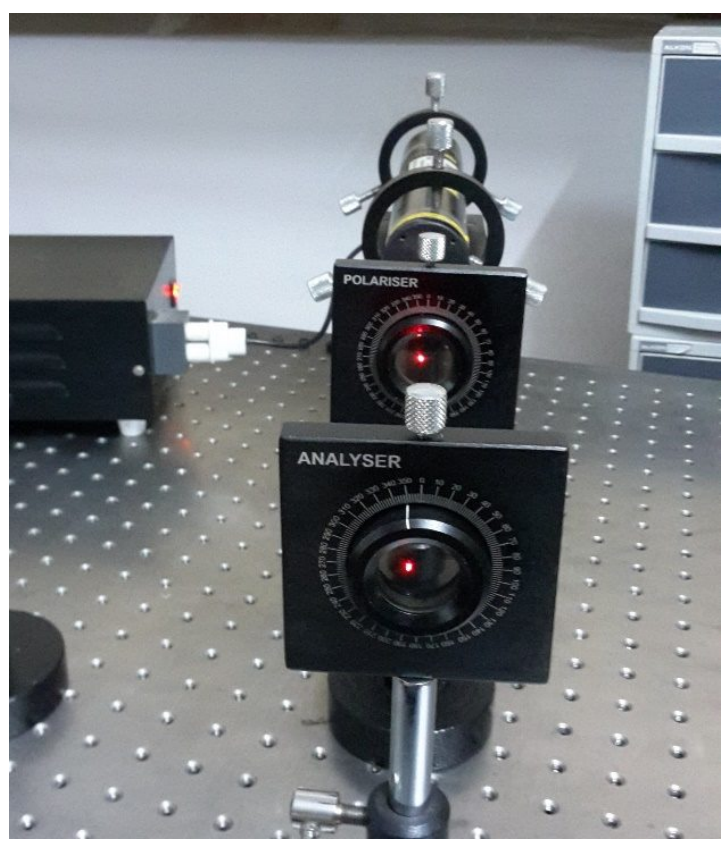

Malus law demonstration at Highest Intensity

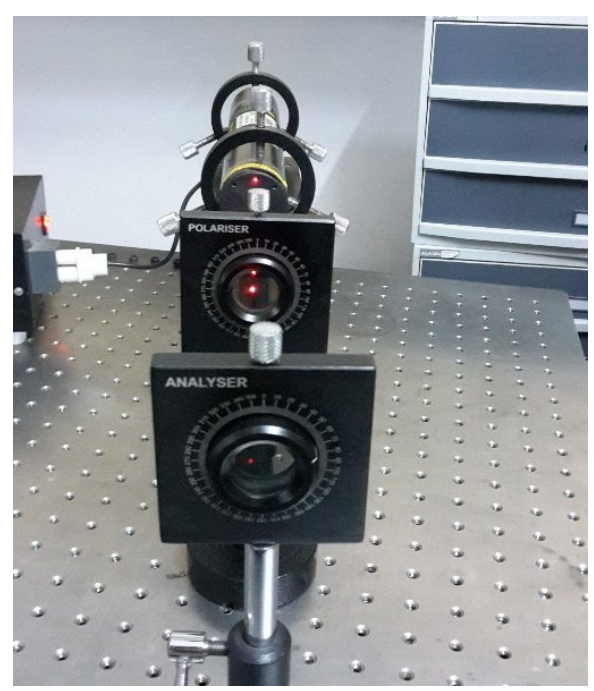

Malus law demonstration at Lowest Intensity

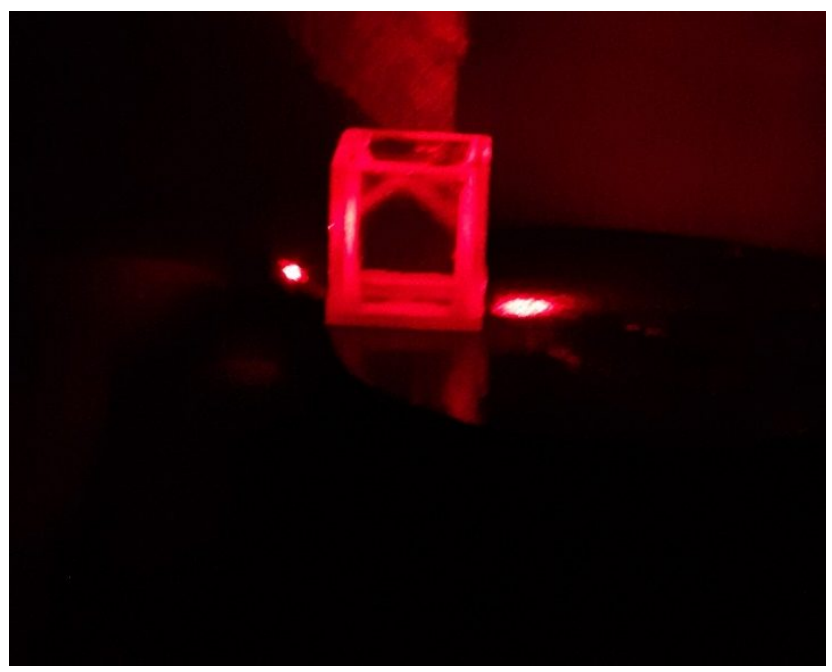

Total Internal Reflection of laser light in water 


\section{RESULTS \& DISCUSSION}

The workshop started with an informal discussion on physics and optics followed by a question session on optics. Many questions were raised by the student during the interaction. Some of them have been listed as under:

1. Is Huygens's principle valid for longitudinal waves?

2. Why is diffraction of sound more evident than that of light?

3. How are stationary waves formed?

4. How does a wave carry energy?

5. What are coherent sources?

6. Does energy conservation hold in Interference?

7. How does light propagate in vacuum?

8. Why light is a wave?

9. Difference between ray optics and wave optics?

The sessions were highly interactive where students came out with their queries and enjoyed the hands-on sessions. The workshop was praised by the students and the teachers for the ease in setup and understanding through the wave optics kit. The hands-on involvement was highly appraised by the students.

Some of the images showing Chapter members interacting with school students during the workshop:

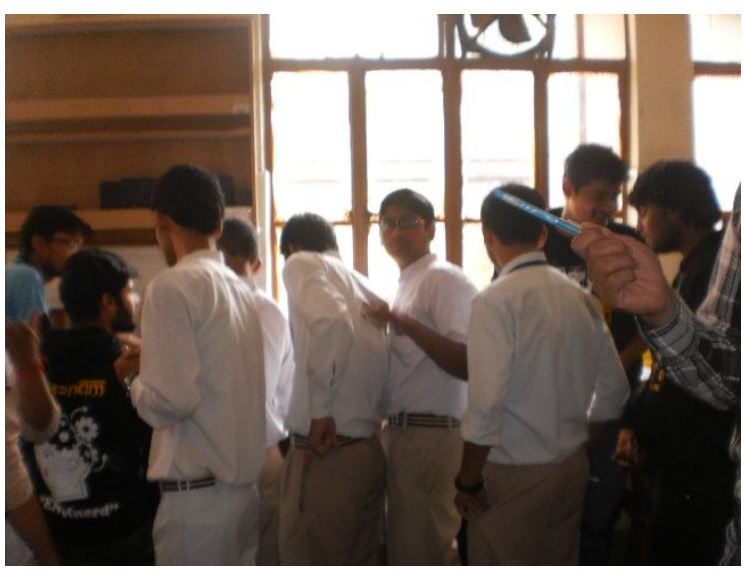

a) Hands-on session in progress.

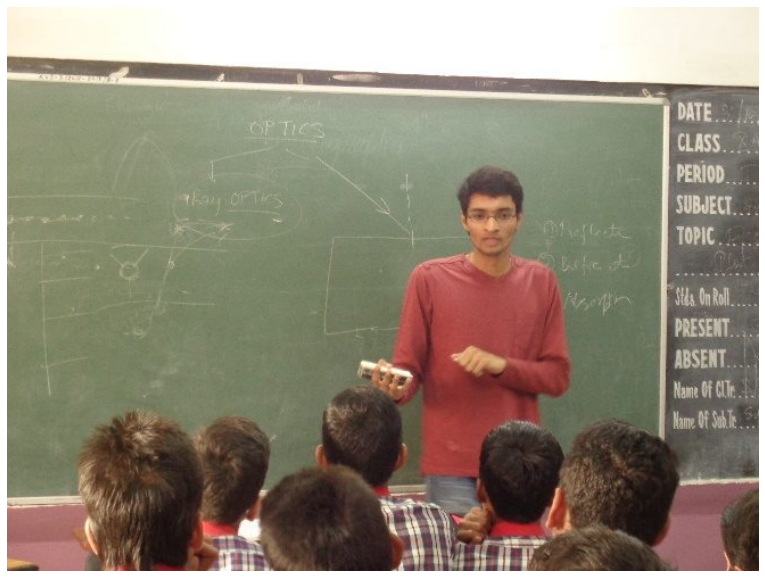

c) Optics theory and question session.

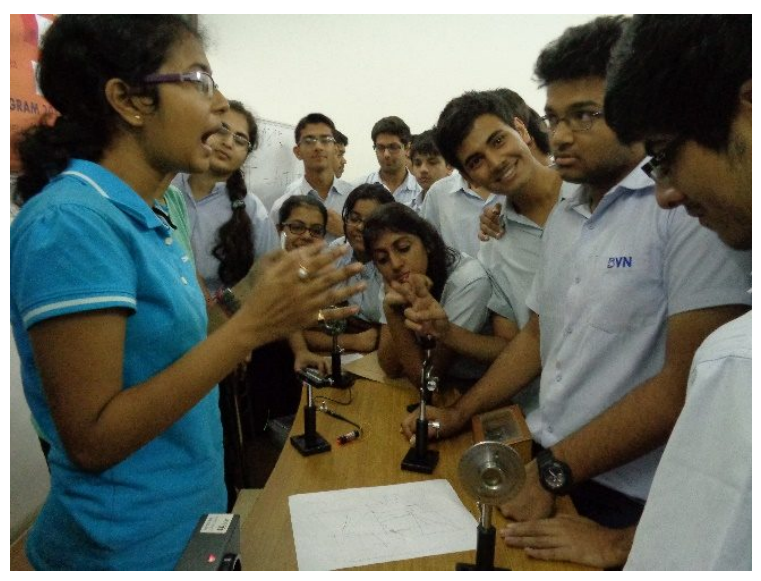

b) Wave Optics Kit demonstration and theory.

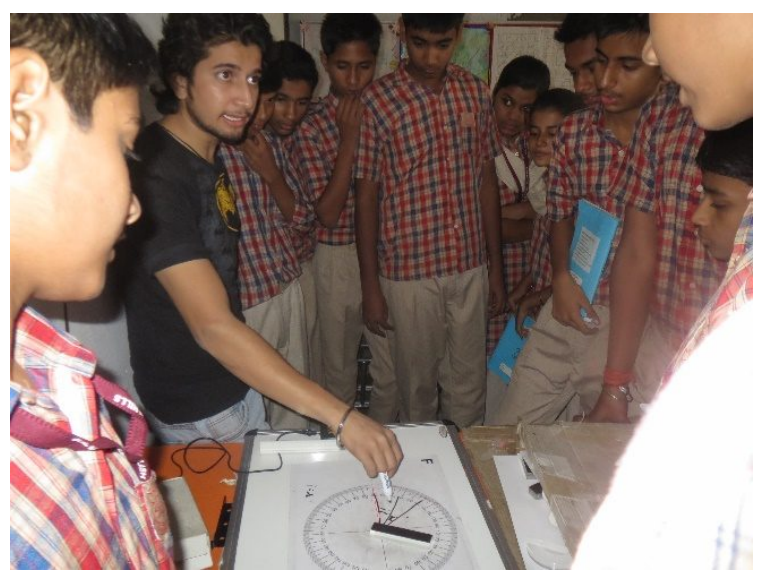

d) Ray optics demonstration to students. 
The response of the students towards the kit and the workshop has also been analyzed. The date is based on 100 random feedback forms.

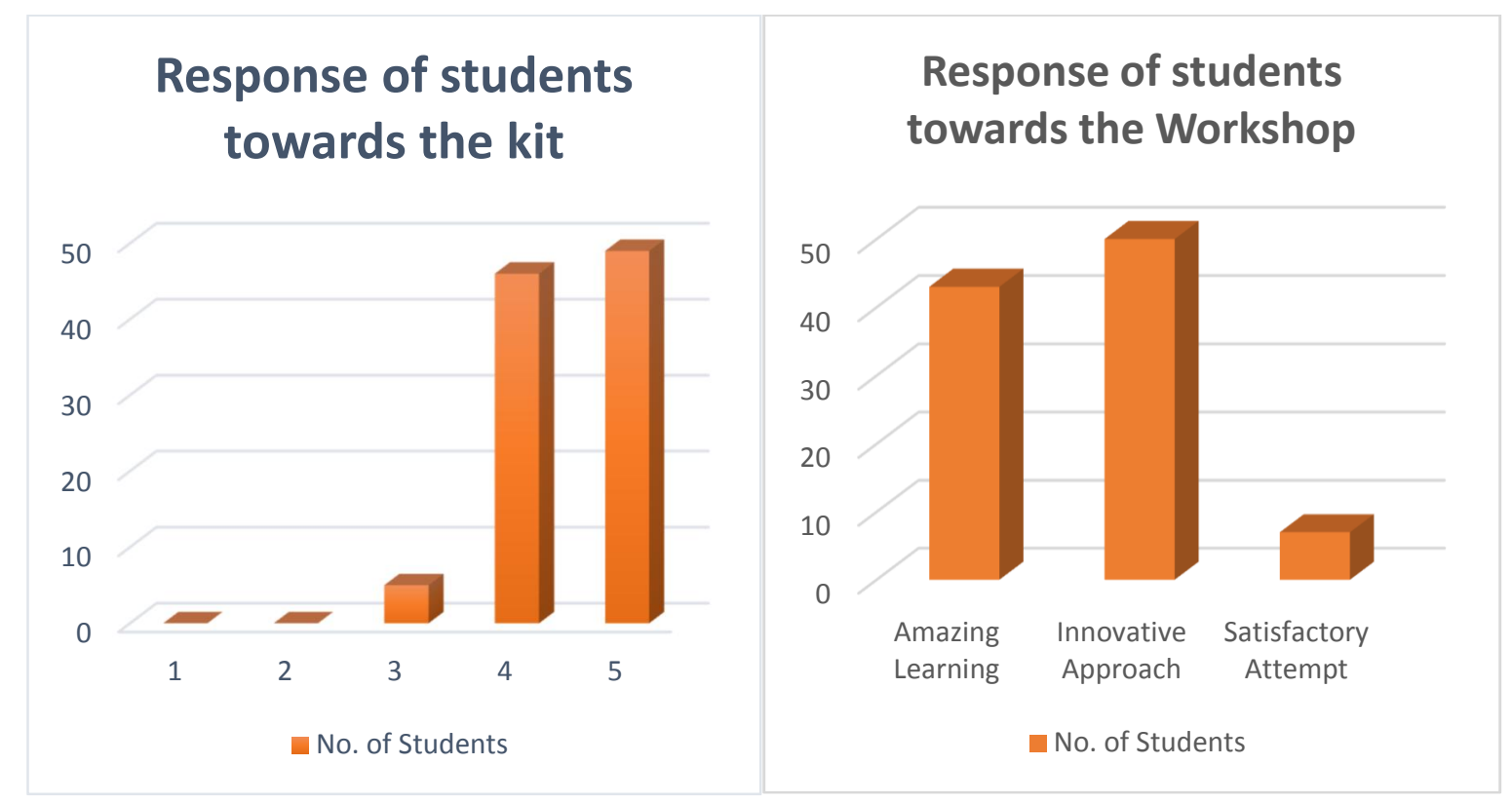

Graph 1. Rating of the kit on a 5 point scale

Graph 2. Response of students towards the workshop (Scale 5 Highest).

\section{CONCLUSION}

The developed kit provides the students with a hands-on experience to wave optics and the knowhow of the experiment. It not only allows the student to learn by themselves but also explore various aspects of wave optics that may not be practically demonstrated in the classroom. The grasp of theoretical concept is backed by the practical exposure provided by the kit. The demonstrations sparked the young minds to explore the area of optics and its wave nature to a greater extent. The kit shall be an asset to the schools for teaching wave optics for the new batches to come.

\section{ACKNOWLEDGEMENT}

One of the authors, Sadashiv Raj Bharadwaj expresses his gratitude towards SPIE, USA for awarding him with the Officer's Travel Grant to attend and present this research paper in SPIE Optics+ Photonics 2016 conference from 27 August - 1 September 2016 in San Diego, CA, USA. University of Delhi at ANDC SPIE Student Chapter is thankful to SPIE, USA for awarding the Optics Outreach Grant, 2014. This outreach activity was organized out of the financial support received under this grant. 


\section{REFERENCES}

1. http://www.ncert.nic.in/NCERTS/textbook/textbook.htm?leph2=1-7

2. Easing wave optics understanding through technology

http://proceedings.spiedigitallibrary.org/proceeding.aspx?articleid=1906584

Proc. of SPIE Vol. 9946 994618-8

Downloaded From: https://www.spiedigitallibrary.org/conference-proceedings-of-spie on 26 Apr 2023 Terms of Use: https://www.spiedigitallibrary.org/terms-of-use 